action of the bowels, it was thought advisable, by Dr. Ward's substitute, to give a drop of croton oil. This produced a slight action of the bowels. It was not, however, until two days after, or nineteen from the time they last acted, that the bowels were relieved of a quantity of scybalous freal matter. From this time the patient became rapidly convalescent.

Remarks. - The case appeared to have been one of inflamma. tion of the cæcum, with attendant paralysis of the muscular coat, and consequent obstruction to the passage of frecs. Mere impaction of fæces does not excite symptoms so formid. able as those under which this man laboured. There can be no doubt but that the preliminary opiate treatment paved the way for the satisfactory action of the croton oil, even if it would not have brought about effective action without it. The contraction of one segment of one rectus muscle, which was a prominent feature of this case, is worthy of notice. Dr. Twining considered contraction of the upper part of this muscle to be almost diagnostic of abscess of the liver; but $I$ think it may be regarded as arising from a sort of protective reflex action, which may be excited in any case of inflammation or lesion of any part of the abdominal viscera or their investment.

For the short notes of the following case I am indebted to my friend Dr. Ansell, of Bow :-

CASE 3. Intussusception, rapidly fatal._J. J-_, a healthy infant, between four and five months old, at the breast, but occasionally fed with milk-and-water, was seized one Friday in November with violent fits of crying, lasting about two hours. He took the breast as usual, and the mother, thinking the child might be griped, gave him some castor oil. On Satur. day, at two A.M., there was hæmorrhage per anum to the extent of about four ounces. Some ammonia and opium were given, but the child scarcely rallied, and died at seven P.M. The post-mortem examination revealed no other morbid ap. pearance save a double invagination of intestine of about twelve inches, formed by a portion of ileum and the cæcum, which had slipped into the colon. The invaginated part felt like a tumour of about the size of a hen's egg. The intestine was of course highly congested.

Remarks. - In the above case, the formidable nature of the attack was at first not suspected; and, indeed, the child did not come under medical treatment until after the loss of blood had occurred, and it was evidently sinking. There were, however, three points characteristic of obstruction from intussusception-namely, the young age of the subject, although it rarely occurs in mere infants; the tumour formed by the invaginated portion, which palpation no doubt would have determined during life; the sudden onset of the attack, and the hæmorrhage per anum, which is said to be distinctive of implication of small intestine.

(To be concluded.)

\section{POPLITEAL ANEURISM SUCCESSFULLY TREATED BY FLEXION OF THE LIMB,}

\section{AFTER FAILURE OF TREATMENT BY COMPRESSION.}

BY S. CURRIE, M.D., C.B.,

DEPUTY INSPECTOR-GENERAL OF HOSPITALS.

IN a paper read before the Royal Medical and Chirurgical Society of London on the 28th of January, 1862, Mr. Ernest Hart gives the results of nine cases of aneurism of the extremities having been successfully treated, either by simple forcible flexion of the limb, or by flexion and compression combined. The case which $I$ am about to relate affords an example of the failure of treatment by compression, and of the cure being ultimately effected by the patient and persevering employment of flexion of the limb. My chief object in draw. ing up an abstract of the following case is to add another instance to the number already published of the successful treatment of cases of aneurism of the extremities by the simple and painless process of flexion of the limb; and it will perhaps be admitted that this case possesses some degree of interest on account of the sudden and unexpected manner in which the cure ultimately took place, after all hope of success had been abandoned. In the latter point of view the case affords an encouraging example of the benefit which may sometimes be derived from the exercise of patience and perseverance.
Private Edward M-, Army Hospital Corps, aged thirtythree, a healthy-looking man, was admitted into the General Military Hospital, Hong-Kong, on the 23rd of January, 1 $1 \div 62$. Stated that about eight days previously he first noticed a slight swelling at the back of the left knee, accompanied by stiffness and pain in walking, and for which he could not assign a distinct cause.

On examination, the veins of the leg appeared to be enlarged, and in the upper half of the popliteal space there was a tumour of about the size of a small orange, rather fiattened, pulsating strongly with each beat of the femoral artery, and ceasing on pressure being applied to the vessel at the groin. On applying the stethoscope to the turnour, a loud bruit was distinctly heard, accompanied by a perceptible thrill, and the swelling could not be sensibly reduced by pressure.

The patient being under the immediate care of Staff Surgeon Hanley and Staff Assistant-Surgeon Maher, who were most indefatigable in their efforts to conduct the case to a successful issue, the treatment by compression was commenced on the 24th of January by the application of a Signoroni's tourniquet to Scarpa's space, and a second one over the artery a little lower down, two compressors being used with the view to mitigate the pain, by the alternate tightening and relaxing of the instruments. No difficulty was experienced in commanding the circulation or in retaining the tourniquets in their position. On the 25 th it became necessary to remove them on account of the severity of the pain.

The same experiment was afterwards repeated on three several occasions, with temporary relaxations to relieve painnamely, from February 8th to the 13th, March 1st to the 7th, and from the 13th to the 20 th of the latter month; and on the last two occasions the compression was aided by the application of ice to the tumour.

The repeated applications of the tourniquets produced the following effects - great emaciation of the thigh, increased hardness of the tumour, and oedema of the leg. On removing the pressure the pulsation invariably returned with undiminished force.

The treatment by compression having failed, I decided upon trying flexion of the leg upon the thigh, combined with more generous fare. On the 27 th of March this was begun by gradually flexing the leg, and after a few days bringing the heel into contact with the nates, and retaining it in that position by means of a web strap and buckle, after the fashion of Mr. Rarey, the celebrated horse-tamer. This had the immediate effect of arresting the circulation in the tumour, to the great relief of the patient. He was allowed to move about on crutches, the foot being supported by a long sling passing over the shoulder. Complete flexion during the first few days caused pain in the knee, but not to an inconvenient extent, and it was not necessary to relax the strap. The pain appeared to be the effect of the stretching of the integuments over the patella, indicated by a certain degree of heat and redness, and which chloroform liniment had the effect of relieving. The collateral circulation soon became very distinct and strong; there were therefore good grounds for concluding that the cure would gradually be effected by the deposition of fibrinous laminæ in the tumour.

On the ninth day the leg was extended to the semiflexed position; and on carefully examining the aneurism the pulsation was found to be feeble, and the bruit almost inaudible. The flexion treatment was resumed, and continued to the 20 th of June. The patient soon became reconciled to his leg being tied up, and his general health was very good. On each occasion that the leg was extended for the purpose of ascertaining the progress of the cure, the returning pulsation in the tumour, though feeble, could be distinctly felt. Hitherto the treatment had been attended with a tantalizing amount of successjust sufficient to encourage the hope that perseverance would eventually be rewarded with a perfect cure. At length de. spairing of being able to effect complete consolidation of the tumour, it was deemed advisable to abandon the flexion process, and to have recourse to ligature of the artery. As a preparatory step to this operation, the strap was removed, and the limb straightened as much as practicable, for a considerable degree of contraction of the knee had taken place from longcontinued flexion. On returning to the patient the following morning-viz, the 21 st of June, the unlooked-for discovery was made that the pulsation of the tumour had entirely ceased, and careful examination with the stethoscope failed to detect the faintest bruit.

It is only necessary to add, in reference to the further his. tory of this case, that from this time there was no return of pulsation, and the cure was in every respect complete. Ths. 
subsequent treatment was mainly directed to straightening the limb to the full extent, and whicb, I doubt not, will eventually be attained. Meanwhile, an opportunity offered of sending the patient to England. He was accordingly invalided, and em. barked at Hong.Kong on the 3rd of August.

Hong-Kong, 1862.

REPORT OF A

\section{CASE OF HEPATIC ABSCESS BURSTING EXTERNALLY, AND BEING CONNECTED WITH THE COLON.}

By R. DOMENICHETTT, M.D., SERGEON, 75TH REGIMENT.

Private John $R-$, 75th Regiment, aged twenty-three, tall, and of slight conformation, served in India three years, during which period he had frequent attacks of fever and dysentery. In December, 1S61, he was first treated for acute dysentery, when stationed in Calcutta. Tpecacuanha in large doses (twenty to forty grajns) was prešcribed, according to the method adrocated by Dr. Scott Docker in 1858, which has been found so beneficial and effective in this formidable dis. order. In this instance the acute symptoms were speedily overcome, as, by reference to the register, I find that he was admitted into hospital on the 17 th December, and discharged on the $22 \mathrm{nd}$ of the same month; but two relapses are reported to have occurred, as he was subsequently in hospital with the same complaint for thirty-nine days.

He embarked for England with his regiment on the 24th of February, 1862, and appears to have suffered at times on the voyage. He was able to perform the duties of hospital orderly on his arrival at Plymouth in $J$ une, but was compelled to report himself sick on the 23rd of A ugust, on account of pain in the bepatic region, accompanied with dysentery.

On the 27th of September, Assistant-Surgeon Millar, who had charge of the patient, first noticed a swelling in the right side, corresponding with the two lower false ribs behind, characterized by evident fluctuation and great pain ; considerable constitutional disturbance was also present. The urine was strongly acid, sp. gr. 1016, with copious deposits of lithates. Rigors alternating with profuse perspirations, and all the symptoms of hectic, set in. A remarkable feature was also noticed : percussion elicited a resonant sound in the vicinity of the abscess, indicating the presence of air, which was a source of some difficulty in the diagnosis. It was presumed that the abscess had some comnexion wilh the intestines, through which alone the ingress of air could be nccounted for. The question now arose, whether it was desirahle to evacuate its content with a trocar, or to leave it to burst spontaneously. The presence of air in the tumour was regarded as a contra-indication to the operation and on Oct. 19 th, the abscess, which had attained the size of an orange, gave way, and about half a pint of thin ill conditioned-looking pus mixed with blood was discharged, followed by great relief to the patient. His strength was supported by stimulants, the discharge continuing unabated and in the course of two or three days an extensive slough of the integuments in the vicinity of the abscess took place, resulting in an aperture of an oval shape, the long diameter of which measured three inches, and through it could be seen the free margin of the liver and folds of intestine, all presenting a black and sloughy condition. The discharges from the bowel were also frequent, and resembled in appearance what came from the abscess. He lingered in this state until the $26 \mathrm{th}$ of October, when he died.

The autopsy, twelve hours after death, confirmed the diagnosis, as a connexion was found to exist between the intes tines and the walls of a large abscess occupying the cavity between the abdominal parietes and the ascending colon, connected superiorly with the base of the right lobe of the liver which was pervaded by a large abscess running into that just described. The structure of the liver was also dotted with secondary abscesses, and varying in size. The liver weighed $4 \mathrm{lbs} .9 \mathrm{oz}$. The contents of the thorax were healthy, with the exception that some pleuritic adhesions were found corresponding with the lower lobe of the right lung, the structure of which, from its contiguity to the diseased liver, was congested. The kidneys were healthy, and weighed between five and six ounces.
Stomach and intestines: Some congestion existed at the cardiac extremity of the stomach. The rectum and colon were pale and thickened, also studded at intervals with large ulcers of long standing. The ascending colon, from its proximity to the abscess, had its walls much thickened, and the opening of communication was of considerable size. Small intestines : There were a few patches of congestion; but they presented no other appearance of disease.

Under the microscope the lobules throughout the greater portion of the liver were seen to be in a state of fatty degeneration, these in many instances having lost their normal appearance, and consisting entirely of faí cells. This was particularly noticed in a section taken from the neighbourhood of one of the secondary abscesses, in which the gradual transition from the healthy lobule to a state of fatty degeneration was very apparen. Devonport, 1863.

\section{d arrut}

\section{OF THE PRACTICE OF}

\section{MEDICINE AND SURGERY IN THE}

\section{HOSPITALS OF LONDON.}

Nulla est alia pro certo noscendi via, nisi quam plurimas et morborum et dissectionum historias, tam aliorum proprias, collectas habere et inter se com parare.-Morgagn. De Sed. et Caus. Morb., lib. 14. Procnium.

\section{KING'S COLLEGE HOSPITAL.}

DEEP-SEATED TUMOUR OF THE THIGH ; OPERATION FOR ITS REMOVAL; SUDDEN DEATYY THIRTY HOURS AFTERWARDS

(Under the care of Mr. Henry Smith.)

In going over the details of the following case, - the notes of which were taken by Mr. Ferris, the dresser of the patient,the question will arise as to the cause of death. If it had been an operation of ovariotomy, we should have unhesitatingly pro. nounced it the result of shock; but in the present instance it can hardly be so considered. We incline to the opinion that chloroform had much to do with it, from the manner in which the symptoms presented themselves during the last hours of life, and remembering at the same time that the patient was fully under its influence during a necessarily somewhat protracted operation, at which but very little blood was lost. Nevertheless, she appeared to have recovered from the immediate effects of the chloroform.

B. S-, aged thirteen, a very tall girl for her age, pallid, and rather thin, was admitted on the 17 th of January, with tumour on the upper part of the left thigh. Upwards of four years ago she fell upon the front part of the thigh, and experienced so much pain in the part that she was compelled to keep to her bed for six weeks. Soon afterwards a swelling appeared at the seat of the injury, and this gradually increased in size. In January of last year she was seen by an eminent surgeon, who proposed to perform an operation, and went to the house of the patient prepared to do it; but, after a careful examination, it was deferred. Subsequently she saw Mr. Ferrusson and Mr. Henry Smith, both of whom considered that the tumonr was movable, and that if it increased or became painful it should be taken away. This was about six months prior to the above date; and subsequently the tumour had both increased in size and become more painfal, so that the girl was admitted for the purpose of having it removed. On examination, there was a great fulness of the upper part of the thigh, and the superficial veins were much enlarged. There was a distinct, hard, movable tumour, extending from about three inches below the anterior spinous process to the commencement of the lower third of the thigh, measuring about five inches in length and three and a half or four inches in breadth. Its upper and lower margins were pretty well defined; but its lateral edge seemed to glide into the surronnding parts. When the thigh was exteniled the tumour was neither defined nor movable; but when the limb was flexed, and the extensor muscles relaxed, the limited and movable character of the 